\title{
REFORMA AGRÁRIA E LAND REFORM: movimentos sociais e o sentido de ser um sem-terra no Brasil e na África do Sul ${ }^{1}$
}

\author{
Marcelo C. Rosa*
}

\begin{abstract}
Este trabalho apresenta os resultados de uma pesquisa comparada sobre a atuação do Landless People's Movement (LPM), da África do Sul, e do Movimento dos Trabalhadores Rurais SemTerra (MST), realizada entre 2005 e 2009. No lado brasileiro, impera a ideia de reforma agrária, ou seja, uma ação política voltada para o uso produtivo ou agrícola da terra, que tem, como pano de fundo, critérios legais de produtividade. Na parte sul-africana, vemos o embate se estruturar sob a nomenclatura de land reform, slogan que remete a uma mudança na distribuição do território, visando à reparação das injustiças cometidas pelos governos do apartheid. Sendo assim, indicamos que esses dois casos comportam tipos diferentes de sujeitos da ação política. Tendo como referentes agentes históricos distintos, os movimentos sob análise, nesses dois países, procuram se legitimar por meio de diferentes "grandezas" que justificam suas existências e suas lutas. Neste artigo, procuraremos apresentar as especificidades de cada um dos sem-terras desses movimentos, a partir das suas formas sociais de "engrandecimento e justificação social" diante de suas bases e do Estado.
\end{abstract}

PAlAVRAS-CHAVE: sem-terra, reforma agrária, África do Sul, movimentos sociais, MST.

\section{INTRODUÇÃO²}

A comparação entre o Movimento dos Trabalhadores Rurais Sem-Terra do Brasil (MST) e o Landless Peoples Movement da África do Sul (LPM) já foi tema de Rosa $(2007,2008)$ e Balleti et al. (2008). ${ }^{3} \mathrm{O}$ primeiro comparou a relação desses movimentos com o Estado. O segundo procurou

* Professor do Departamento de Sociologia da Universidade de Brasília - UnB. Pesquisador do CNPq. Campus Universitário Darcy Ribeiro - ICC Centro - Asa Norte. Cep: 70910-900 - Brasilia -DF - Brasil.marcelocr@uol.com.br

${ }^{1}$ A pesquisa que sustenta este texto foi realizada com apoio do CNPq e da Fundação Ford. Essa pesquisa vem sendo realizada conjuntamente com Antonádia Borges a quem agradeço por ter me introduzido e debatido diversas ideias que estão no texto e também por sua cuidadosa revisão. Sou grato também aos pareceristas anônimos que ajudaram a esclarecer diversos pontos do artigo.

${ }^{2}$ Neste texto, não trataremos da organização desses movimentos, de suas acões coletivas ou formas de recrutamento. Apesar de importantes, tais questões extrapolam os limites da discussão sobre a noção de sem-terra em cada país.

${ }^{3}$ Ao contrário do que as informações dos entrevistados do artigo de Balleti et al (2008) sugerem, nossa investigação contesta a afirmação de que o LPM esteja morto. Tendo realizado pesquisa contínua com membros desse movimento entre 2005 e 2010, observei mudanças nas táticas e estratégias do movimento, bem como uma regionalização de suas ações na província de Kwazulu-Natal. Esse processo parece ter levado à crescente distinção entre o LPM e o MST, objeto de outro texto, em elaboração. elencar as diferenças na forma de organização e mobilização de cada um, apontando para os possíveis limites das redes de movimentos sociais formadas nos últimos anos. Esses textos partem da premissa de que os movimentos são comparáveis porque ambos representam os sem-terra em cada um dos países. O que nenhum deles parece colocar em questão é justamente o fato de que terra e sem-terra podem não ter o mesmo sentido e o mesmo significado político em cada um dos países. Se os sentidos dos objetos aos quais se dedicam, em suas lutas, não são necessariamente os mesmos, os próprios movimentos podem, ao fim e a ao cabo, não ser exatamente equivalentes. A comparação, no caso aqui proposto, não partirá, portanto, da aceitação da categoria sem-terra como equivalente universal, mas de sua reconstrução feita pelas pistas deixadas pelas agências dos próprios movimentos no espaço público.

A análise, que todavia se pretende comparativa, tomará como foco, seguindo os passos de Boltanski (2000), a situação de disputa na qual cada um dos movimentos emerge como representante de demandantes por terra. Na visão desse autor, 
nessas situações os sujeitos envolvidos são chamados a explicitamente apresentar provas de sua grandeza e de sua importância. Tais provas permitiriam, ao dessingularizar a posição dos actantes, ${ }^{4}$ constituir aquilo que Latour (2005) chama de coletivos. Nessa perspectiva, tanto MST como LPM seriam coletivos que se organizam associando a noção de sem-terra a ações, símbolos, discursos, documentos e histórias que, por sua vez, constituem sentidos específicos a cada movimento. Será por meio da análise desses objetos, postos nas provas constituídas em situações públicas, que procuraremos, ao longo do texto, descrever os diferentes conjuntos que, em cada Movimento, dão sentido social aos sem-terra no Brasil e na África do Sul.

Partindo dessas premissas, procuramos apontar especialmente para o fato, negligenciado nas comparações já citadas, de que, se existem diferenças cruciais nos termos empregados em cada país, as relações entre terra e sem-terra não podem ser tomadas como estáveis, inequívocas ou unívocas: enquanto o movimento brasileiro luta por “reforma agrária”, o movimento sul-africano luta por uma "reforma da terra". Por fim, defenderemos a hipótese central de que questões raciais próprias de cada país e a relação com a agricultura são elementos-chave para o entendimento dessa diferença entre a terra e o sem-terra em cada lugar.

\section{QUANDO OS MOVIMENTOS SE ENCONTRAM}

Para começar nossa análise, é preciso considerar que a comparação entre MST e LPM não

${ }^{4} \mathrm{O}$ termo actante, tão familiar aos leitores de Bruno Latour, foi cunhado pelo linguista Algirdas Julien Greimas. Grosso modo, é plausível afirmar que seu modelo "actancial" inspira-se nas teorias de Vladimir Propp acerca das estruturas narrativas. Embora a abordagem estruturalista lhes seja, desde um olhar panorâmico, comum, Greimas sustentou que o actante ocupa papéis actanciais a depender da trajetória da narrativa. Portanto um actante não é o mesmo que um personagem e, consequentemente, não pode ser caracterizada de forma isolada, independentemente da trama. A formulação de Greimas foi apropriada por diversos intelectuais, posteriormente descritos como dedicados a pensar a "crise do sujeito", como Julia Kristeva. Na obra de Latour, esse incômodo com a hegemonia do sujeito como único ator plausível se dissipa com a aposta no conceito de actante, passível de ser definido somente no processo de recomposição do social. existe apenas na cabeça dos pesquisadores que se dedicaram a conhecê-los melhor. Desde a fundação do LPM, os dois movimentos têm mantido intercâmbios, no Brasil e na África do Sul, por meio da La Via Campesina, movimento internacional ao qual ambos são filiados. A própria pesquisa que deu origem a este texto foi desenvolvida a partir da etnografia de uma das viagens que militantes brasileiros fizeram à África do Sul e dos dilemas que emergiram no contato cotidiano entre as duas organizações.

Em 2005, eu acompanhava um grupo de militantes do Movimento dos Trabalhadores Rurais Sem Terra(MST) que visitava o Landless People's Movement (LPM) na África do Sul. ${ }^{5}$ Durante um dos encontros iniciais, na província de KwazuluNatal, com pessoas ligadas ao movimento, a primeira pergunta feita ao representante do MST foi a seguinte: Por que há brancos (como o próprio militante que discursava) no MST ${ }^{6}$ O questionamento abalou não apenas o militante como o pesquisador que o acompanhava. Até aquele momento, para o militante e para mim, a associação entre sem-terra e sujeitos brancos era absolutamente normal. Afinal, conhecendo a história do MST, sabíamos que o movimento nascera entre os colonos ${ }^{7}$ brancos que organizaram ocupações de terras públicas no sul

${ }^{5}$ Agradeço ao MST e aos militantes Vanderlei Martini e Inês Pinheiro, por me permitirem acompanhá-los em sua viagem pela África do Sul e compartilhar, com eles, as surpresas e angústias de lidar com a questão da terra naquele país. As inquietações que dão origem a este texto são produtos coletivos das inúmeras conversas e situações que tivemos durante um mês de convivência, viajando entre as várias províncias sul-africanas. Peço desculpas se as conclusões deste texto não puderem refletir com exatidão o processo de aprendizado que tivemos naquele período. Agradeço também a Mangaliso Kubheka e a Thobekile Radebe pela generosidade de permitir minha visita.

${ }^{6}$ Nesse encontro, havia um militante branco e uma militante negra do MST. Ele, nascido no Rio Grande do Sul, mas radicado em Minas Gerais, e ela, do estado do Maranhão.

${ }^{7}$ Colono é um termo que se refere a quem se reconhece como descendente de imigrantes alemães, italianos, poloneses, entre outros, que chegaram ao Brasil entre os séculos XIX e XX para viver e se dedicar a atividades laborais no campo. Esta nota é importante por indicar que a narrativa histórica privilegiada por esses narradores busca a Europa dos camponeses como seu berço e também porque sublinha os aspectos positivos (leia-se, produtivos) da ocupação colonial contemporânea no Brasil, obliterando a violência desse processo, em especial no que tange à construção da imagem de terras devolutas, improdutivas, sem gente, à espera de serem cultivadas por sujeitos aptos, ou seja, os colonos. 
do Brasil, no final da década de $1970 .{ }^{8}$ Apesar disso, quase nunca se vê, em textos sociológicos ou nos próprios relatos do movimento, a cor da pele caracterizando os sem-terra deste lado do Atlântico. O LPM, por sua vez, era formado, em sua totalidade, por pessoas negras que, no pós-apartheid, reivindicam a posse formal das terras em que viviam ou em que viveram antes de serem removidas pelo regime racista. Não demoraria muito para compreendermos que a questão não era simples e remeteria aos próprios fundamentos da ação de ambos os movimentos. A cor do sem-terra, como veremos nas partes seguintes, passaria a se impor para o entendimento não apenas das bases de sua ação coletiva, mas, principalmente, do que se entende como luta por terra em ambos os lugares.

Juntamente com a cor do sem-terra, chegamos a outro ponto importante que distingue esses movimentos em seus discursos e documentos: o slogan de sua luta. No Brasil, todos os documentos do MST e discursos coletados durante a pesquisa se referem a uma luta por reforma agrária. Já na África do Sul, usando os mesmos procedimentos de pesquisa, nos deparamos com a referência à land reform, ou seja, reforma da terra.

Tomando como objeto de análise as formas pelas quais os militantes, os movimentos, os sociólogos e os governos justificam e engrandecem (no sentido de atribuir escalas e magnitudes para definir relevâncias e importância de maneira relacional, como descreve Boltanski, 2000) suas ações em esquemas teóricos, raciais, slogans, documentos e símbolos, pretendemos demonstrar que a associação entre a cor dos sem-terras e suas respectivas lutas pode ser um caminho fértil para o melhor conhecimento do sentido de suas ações. Essa comparação visa, mais do que a esclarecer e definir o verdadeiro significado dessas lutas, a criar obstáculos e desafios epistemológicos essenciais, no sentido proposto por Stengers (2002), para aqueles que estão acostumados ao campo dos estudos rurais no Brasil e na África do Sul.

Em termos metodológicos, a forma de expo-

${ }^{8}$ Maiores detalhes sobre essas ocupações estão desenvolvidos em Rosa (2009) e Sigaud, Rosa e Macedo (2008). sição desse problema deriva das perspectivas desenvolvidas por Luc Boltanski e Laurent Thevenot, dentre outros, em torno de uma sociologia das ações sociais normativas, orientadas pelas justificações postas em prática pelas pessoas em momentos de disputa. Mais especificamente, procuraremos seguir sua sugestão de analisar a "maneira pela qual as pessoas criam causas, boas causas, causas coletivas" e como essas operações dependem sempre de um engrandecimento das pessoas, dos discursos e de todos os demais objetos postos nessa contenda (Boltanski, 2000, p.26 et passim). Para esses autores, a fim de se tornar grande, outros poderiam dizer "digno" de participar em uma disputa, as pessoas agenciam objetos e situações em estados sociais, de forma a criar equivalências cognoscíveis pelos partícipes. São as reconstruções desses estados que permitem que as relações sociais sejam analisadas a partir de tais paradigmas, quenão são parâmetros de ação política extrínsecos aos contexto investigado, mas, ao contrário, tecidos conceitualmente pelos sujeitos em luta. Ofundamental, nesse tipo de construção sociológica, éo reconhecimento pelos actantes das provas que são apresentadas de maneira legítima para justificar a existência e a construção de uma determinada relação social. Tomando de empréstimo a ideia de Bruno Latour (2005) de que devemos reconstruir as associações que permitem a existência social de nosso objeto de pesquisa, procuramos demonstrar as formas como as ações de movimentos se conectam com a história e com a sociologia de cada país.

Em nosso caso, estaremos colocando em perspectiva a forma pela qual, na situação acima descrita, os sem-terra da África do Sul e do Brasil, usando um conjunto específico de provas (como cores, slogans e, também, conceitos sociológicos), em situações igualmente particulares, organizam o que temos chamado genericamente de lutas por terra.

\section{A HOMOLOGIA ENTRE SEM-TERRA E AGRÁ- RIO: discursos e narrativas como provas}

O primeiro passo é tomar como ponto de partida uma análise das formas como o MST, por 
meio de seus militantes e documentos, se justifica como um actante grande ou valorizado nas lutas por terra no Brasil. Quais são os objetos e as provas que lhe permitem mobilizar pessoas, recursos e teorias que, ao tornarem-no cognoscíveis, criam o próprio valor público do sem-terra na situação de emergência desse movimento?

Tendo em vista que nossa pesquisa teve como questão inicial uma comparação institucional dos movimentos e de seus respectivos lugares de ação em cada um dos países, procuramos utilizar, como material analítico, os informes produzidos sobre quem são e o que demandam os sem-terra de cada país de seus respectivos Estados, a fim de construir uma resposta possível a essas questões.

\section{QUEM SÃO OS SEM-TERRAS DO MST?}

Nesta seção, apresentaremos textos produzidos pelo MST ou por seus membros que buscam definir seus objetivos e suas bases sociais. Escrevendo para uma publicação que tenta dar conta das várias acepções que o termo terra pode ganhar no Brasil, Ademar Bogo, uma das principais lideranças nacionais do MST, assim define o que seriam os sem-terras na sua perspectiva: "Inicialmente é um substantivo composto que designa a condição social de quem vive do trabalho agrícola e tem aptidão para o mesmo, mas não possui sua própria terra.” (Bogo, 2004, p.419).

Na proposta de reforma agrária do MST de 1995, republicada em uma coletânea organizada por outro de seus principais líderes, encontramos outra definição que alude aos mesmos elementos:

Quem consideramos sem terra: trabalhadores rurais que trabalham a terra nas seguintes condições: parceiros, meeiros, arrendatários, agregados, chacreiros, posseiros, ocupantes, assalariados permanentes e temporários e pequenos proprietários com menos de 5 hectares. (Stédile, 2005, p.178).

Mesmo distantes no tempo, nos dois momentos discursivos, o MST se apresenta diante de outros sujeitos (em um caso, o público univer- sitário e, no outro, um segmento maior da sociedade, incluindo o Estado) de forma a ser considerado legítimo. Ambas as definições são bem próximas àquelas que leremos nos primeiros manifestos dos acampamentos de sem-terra no sul do Brasil, encontradas no livro de Méliga e Janson (1982) e na tese de Gehlen (1983), dentre outros.

Tomando as formas de apresentação escrita em cada um dos casos, podemos pensar cada um dos elementos associados à condição de sem terra como um objeto que é usado como prova de sua grandeza (ou dignidade) pública. Nessas situações, o trabalho produtivo na terra - resultado da aptidão para atividade rural - aparece como a justificativa para que se venha a receber um lote. A disputa, que levará a certo tipo de ação política por parte do movimento e por parte do Estado, como veremos abaixo, se torna possível justamente a partir do reconhecimento - pelo MST e por outros actantes - da relação obrigatória de equivalência entre terra e espaço produtivo para a agricultura.${ }^{9}$ É importante notar que o sem-terra e a terra não podem ser vistos ou analisados em tais manifestos como coisas que possuem um valor próprio ou independente de sua relação com outros objetos. Ambos precisam ser engrandecidos por outros elementos, como trabalho e agricultura, que permitem sua diferenciação diante de um outro tipo de terra e de um outro tipo de sem-terra: aquela que não é usada para a agricultura e aquele sujeito que, apesar de não possuir terras, não trabalha ou não tem aptidão para usá-la produtivamente.

Definindo-se como sujeito a partir dessas associações, o MST, nos mesmos documentos, aponta como sua principal demanda e seu principal objetivo a realização de uma "reforma agrária" que faça parte da elaboração de um "novo modelo agrícola" para o país.

Quadro 1 - Grandezas mais frequentemente associadas ao termo sem-terra em documentos do MST Sem-Terra

terra - trabalho - aptidão - modelo agrícola reforma agrária - desenvolvimento

${ }^{9}$ É importante notar que "Terra para quem nela trabalha" foi um dos slogans do MST adotado entre 1984 e 1988. 
Entender, a partir da sua expressão em discursos públicos do Movimento, o sentido dessas provas e associações entre a figura do sem-terra e todos estes objetos que povoam os documentos do MST, não é possível sem que consideremos essas características como construídas a partir de uma disputa.

Na leitura de seus documentos, a disputa principal do MST se trava contra o "latifúndio", como modelo produtivo e como unidade política. Em todos os documentos publicizados pelo MST ao longo dos últimos 20 anos, esse é o inimigo a se combater: a grande propriedade, associada a diversas outras provas cujas grandezas ${ }^{10}$ seriam sempre negativas como:

Quadro 2 - Grandezas mais frequentemente associadas ao termo latifúndio em documentos do MST

\begin{tabular}{c} 
Lotifúndio \\
\hline $\begin{array}{c}\text { monocultura - especulação - improdutividade - } \\
\text { violência - exploração do trabalho }\end{array}$ \\
\hline
\end{tabular}

É importante notar que as categorias que constroem o sem-terra do MST não são necessariamente correspondentes àquelas usadas para destituir de valor seus contendores. Não estamos em um jogo de oposições, no qual os elementos teriam uma relação de equivalência permanente, calcada em uma oposição substantiva. Trata-se bem mais de uma contenda na qual se joga em diversas frentes, associando todos os elementos disponíveis para a caracterização de um determinado estado de legitimidade do sem-terra ou de deslegitimação do latifúndio.

Para um melhor entendimento dos quadros acima apresentados, precisamos ter em mente que o sem-terra não foi uma criação do MST e seu inimigo, o "latifúndio", tampouco. Esses termos fazem parte de um agenciamento que leva em conta o valor atribuído a eles em uma determinada situação social. Em Rosa (2009), procuramos demonstrar que a categoria sem-terra surge da interação entre demandas por terra e políticas de Estado,

${ }^{10}$ Os objetos relacionados no quadro representam elementos associados ao latifúndio em documentos do MST datados de 1985, de 1995 e de 2009. mais precisamente, forma-se como uma categoria para determinadas políticas públicas. Naquele momento, apontamos o governo de Leonel Brizola, no Rio Grande do Sul (1959-1963), como uma das fontes primordiais do termo. ${ }^{11}$ No referido contexto, o sem-terra era identificado como um agricultor pobre, que não tinha acesso à terra. A principal causa disso, apontada em diversos documentos daquele governo, era a predominância do latifúndio na região. Paulo Schilling, um dos responsáveis pelo programa de reforma agrária daquele governo e também um dos fundadores do primeiro movimento a usar a expressão sem-terra - o Movimento dos Agricultores Sem Terra (MASTER), fundado no estado do Rio Grande do Sul em 1960 define assim a situação:

Partindo da premissa inquestionável de que a infraestrutura agrária [...] está condenada e deve desaparecer, vejamos inicialmente quais os objetivos a alcançar com a reforma agrária:

1) eliminação do latifúndio [...] como instituição e latifundiário como classe (Schilling, [1965], 2005, p.234).

Outro elemento que não pode ser desprezado nesse coletivo de provas e actantes é a forma como o Estado, por meio de sua legislação que permite o acesso legal à terra, atrela os termos reforma agrária e sem-terra. No Estatuto da Terra (Lei $\mathrm{n}^{\circ} 4.504$, de 30 de novembro de 1964), principal instrumento legal vigente para lidar com as demandas de movimentos como o MST, encontramos as seguintes passagens:

Art. 25. As terras adquiridas pelo Poder Público, nos termos desta Lei, deverão ser vendidas, atendidas as condições de maioridade, sanidade e de bons antecedentes, ou de reabilitação, de acordo com a seguinte ordem de preferência:

I - ao proprietário do imóvel desapropriado, desde que venha a explorar a parcela, diretamente ou por intermédio de sua família;

II - aos que trabalhem no imóvel desapropriado como posseiros, assalariados, parceiros ou arrendatários;

${ }^{11} \mathrm{O}$ trabalho de Bernard Alves (2010) avança substantivamente na compreensão da origem do termo no Brasil, sendo uma referência fundamental para entendermos o conjunto de associações que estavam presentes quando da constituição original do termo. 
III - aos agricultores cujas propriedades não alcancem a dimensão da propriedade familiar da região;

IV - aos agricultores cujas propriedades sejam comprovadamente insuficientes para o sustento próprio e o de sua família;

$\mathrm{V}$ - aos tecnicamente habilitados na forma dá legislação em vigor, ou que tenham comprovada competência para a prática das atividades agrícolas.

$\S 1^{\circ} \mathrm{Na}$ ordem de preferência de que trata este artigo, terão prioridade os chefes de família numerosas cujos membros se proponham a exercer atividade agrícola na área a ser distribuída. $\S 2^{\circ}$ Só poderão adquirir lotes os trabalhadores sem terra, salvo as exceções previstas nesta Lei. (grifos meus).

Como vemos, para o Estado brasileiro, somente poderá ocorrer reforma agrária se existirem sem-terras que sejam trabalhadores competentes para realizar práticas agrícolas. Ao trazer esses elementos variados, queremos ressaltar que o MST, quando surge (em 1985) e tenta se impor como actante legítimo nas disputas por terra, procura agenciar elementos que possam ser identificados por outros como justificadores de sua ações e engrandecedores ou dignificadores de sua conduta. Ao pretender tomar para si a representação dos semterra, o MST carregou uma série de provas que davam conta da importância dessa tarefa e que havia sido posta em jogo em outras disputas passadas.

Se a relação entre sem-terra e latifúndio já era clara, por exemplo, no governo de Brizola, a construção do latifúndio como um problema para a nação brasileira se devia também ao legado que a sociologia e as ciências sociais nacionais, de forma mais geral, deixaram desde seus primeiros momentos. A esse legado o MST se filia publicamente por meio de seus veículos editoriais.

O reconhecimento de certos aspectos do chamado pensamento social brasileiro e das grandezas por ele acionadas é posto em jogo pelo MST, como podemos evidenciar na coletânea "A questão agrária no Brasil”, organizada por João Pedro Stédile (principal liderança do movimento) e publicada pela editora também ligada ao movimento. Nos cinco volumes organizados, temos manifestos de movimentos e de partidos políticos colocados lado a lado com textos acadêmicos sobre os dilemas dos processos sociais agrários para a esquerda brasileira. A publicação, literalmente, associa visões intelectuais e políticas que ajudam a legitimar a causa defendida pelo MST; a principal delas, sem dúvida, é a condenação do latifúndio como matriz social, política e econômica. Tal associação permite ao movimento se apresentar criticamente diante de sua base, dos acadêmicos e do próprio Estado (actantes que também se orientam pelos mesmos termos, quando se referem à questão da terra no Brasil), legitimando um campo cognitivo definido pela expressão “questão agrária”.

Esse breve apanhado, a partir do múltiplo universo de objetos postos à prova em diversas situações na qual a terra aparece com um elemento fundamental, é importante para compreendermos também porque, no Brasil ela é sempre associada à realização de uma reforma agrária. Se a terra aparece invariavelmente relacionada à questão agrária, nada mais lógico que os programas políticos e acadêmicos (especialmente os publicados na coletânea de Stédile) deem ênfase à reforma agrária como uma ação legítima e necessária.

É preciso esclarecer que, ao abordar esse universo de objetos que constituem as chamadas lutas por terra no Brasil dos últimos 50 anos, não estou lhe atribuindo uma origem, e sim uma possível associação que nos ajude a compreender o caso que questão. Não defendo, portanto, a ideia de que devamos fazer uma sociogênese dos termos que aqui usamos, como faz Elias (1989) com os termos cultura e civilização, por exemplo. $\mathrm{Na}$ perspectiva teórica adotada neste texto, o intento é apenas mostrar como tem feito o próprio MST em publicações recentes, que esse sem-terra brancocomo o militante sul-africano nos chamou a atenção - é fruto de uma situação específica. Ele é o agente possível, em nossa narrativa histórica, para conduzir uma transformação da estrutura agrária e agrícola do país, porque, ao longo do tempo, os agricultores comerciais reconhecidos e representados como ideais - principalmente os grandes, mas também os pequenos - foram sempre aqueles de pele branca.

O que vimos até agora é que o MST incor- 
pora, em suas justificações, formas e fórmulas históricas já conhecidas. Por meio de um conjunto específico delas, cria, assim, um "regime de engajamento" em sua luta (Thévenot, 2006). Nesse contexto, é preciso notar que a possibilidade de um militante vir a se sentir digno de participar do movimento passa pela dessingularização da sua situação individual (do corpo biológico ou dos limites de um movimento, partido ou instituição), tornada plausível e possível graças ao agenciamento correto do universo de objetos que vimos acima. Ser sem-terra no Brasil, ao menos no campo discursivo, implica incorporar a relação com a terra que mantinham os colonos do sul do país, que se atribuem uma origem europeia, e, gradualmente, outras categorias de agricultores conclamados às fileiras do MST ao longo dos últimos 25 anos. Sem conexão com esses objetos (como trabalho e agricultura), suas ações não seriam cognoscíveis como dignas (grandes) e poderiam ser vistas como ilegítimas ou injustas por outras parcelas da sociedade ou do Estado.

Em outras palavras, vimos que os sem-terra do MST são o resultado de um agenciamento de narrativas históricas, interpretações sociológicas, marcos legais e situações sociais que estabeleceram uma condição para sua ação. Nesses termos, sem passar pelo crivo da questão agrária e da reforma agrária, não há justificativa social compartilhada para ação dos sem-terra do MST. Tais considerações podem ser vistas como naturais e óbvias para aqueles acostumados com os estudos desse movimento. Porém, quando tomamos contato com outras realidades, como a sul-africana, essa relação de homologia entre sem-terra e agrário desaparece por completo.

\section{QUEM SÃO OS SEM-TERRA DO LPM}

Seguindo o caminho trilhado para conhecer a forma pela qual o sem-terra do MST se apresenta e se legitima no Brasil e fora dele, passamos agora para o outro lado do Atlântico e para as associações que envolvem as ações dos landless (sem- terra, em inglês).

Em sua constituição interina, feita para apresentar o movimento para fora, mas também para aqueles que gostariam de se associar à sua causa, $o$ LPM (Landless People’s Movement) define claramente quem são seus sem-terras:

Nós somos o povo que nasceu do choque entre o colonialismo e neocolonialismo, da invasão de nossa terra pelos países mais ricos do mundo, do roubo de nossos recursos naturais e da exploração forçada do trabalho pelos colonizadores.

Nós somos o povo que nasceu do apartheid, das remoções forçadas de nossos campos e casas, da pobreza nas áreas rurais, da opressão nas fazendas e da fome, da negligência e da doença nos Bantustões. Nós sofremos com o trabalho migrante que levou nossas famílias e comunidades ao colapso. Nós passamos fome em decorrência do desemprego e dos baixos salários. Nós temos visto o parco desenvolvimento de nossas crianças em decorrência da falta de condições sanitárias, água e comida. Nós temos visto nossa terra secar e ser levada pelo vento, porque fomos forçados a viver em lugares cada vez menores.

E, em sua carta de demandas, reivindicam que: “toda a população negra da África do Sul que precisa de terra deve ter o direito à reforma da terra, pois nós todos a perdemos durante o colonialismo e o apartheid."

Aceitando que esses documentos são formas de justificação que permitem ou que permitiram ao LPM tomar um lugar de importância nas disputas por terra nos últimos anos, percebemos, logo em um primeiro momento, que as associações realizadas são muito diferentes das encontradas nos discursos do MST, anteriormente apresentadas.

O objeto fundamental apresentado é o colonialismo (e sua variação contemporânea, o neocolonialismo) como o processo histórico mais amplo para a compreensão do estado atual da questão da terra. Para o LPM, a condição da situação social de sem-terra foi resultado do processo de ocupação do território hoje pertencente ao seu país por holandeses e ingleses, dentre outros, ao longo dos últimos séculos. O termo definidor da ação colonial não é outro senão o roubo das terras habitadas pelos "africanos" ou "indigenous people", categorias que aparecem em distintas ocasiões como 
sinônimas. ${ }^{12}$ A partir do roubo originário, novos objetos seriam postos em relação com a terra, como o preconceito racial, a pobreza, a fome, a migração e o trabalho forçado. ${ }^{13}$

Todavia o colonialismo não aparece sozinho nessa contenda. Sua principal associação é com o apartheid, regime que instaurou oficialmente a diferença de cor como uma diferença social na África do Sul. Para o LPM, o apartheid não começou com a chegada ao poder do Partido Nacionalista em 1948 e com a instalação formal do regime segregacionista. O movimento reconhece que a situação colonial se tornou, ainda mais complicada a partir de instauração das leis que deliberavam sobre os limites para uso do solo permitidos à parte negra da população. O Natives Land Act de 1913 restringia a possibilidade de propriedade negra da terra às chamadas reservas (territórios demarcados especificamente para populações negras africanas) e, em termos percentuais, limitava essas áreas a apenas $10 \%$ do território do país. Ao Natives Land Act se seguiu uma legislação ainda mais restritiva, que criou os meios para um massivo processo de remoção de pessoas negras de área rurais e urbanas, com a concomitante transferência de suas terras para as mãos de fazendeiros brancos, em um processo contínuo que teve seu ápice nas décadas de 1960 e 1970. O único tipo de propriedade rural de terra que se permitia à população negra era, por assim dizer, "comunal”, nas reservas administradas por autoridades tradicionais (chefes locais empossados pelo governo do apartheid), cuja principal função era deliberar sobre a alocação das terras sob sua responsabilidade. ${ }^{14}$

12 Além dos documentos escritos, alguns dos termos aqui utilizados foram ouvidos em discursos, conversas e encontros que envolviam a participação de membros do LPM.

${ }^{13} \mathrm{Na}$ África do Sul, foram criados albergues, nas chamadas townships, para abrigar moradores, em geral homens, das reservas ou bantustões que migravam para trabalhar, principalmente nas minas. Para esses trabalhadores, o salário era calculado sem levar em conta suas despesas com a família, pois sua reprodução social deveria se dar com a terra alocada em tais reservas.

${ }^{14}$ Sobre a alocação de terras por chefes tradicionais, ver o trabalho de Ntsebeza (2005). Segundo James (2007), a imposição dos chefes tradicionais como autoridades para alocação de terra nas reservas foi obra do "The Bantu Authorities Act” de 1951.
Um salto histórico é necessário para compreendermos que essas questões elevaram o tema da terra ao centro dos debates políticos sul-africanos muito antes da existência do LPM. Durante todo o período do apartheid e, especialmente, a partir da década de 1970, organizações não governamentais (ONGs) atuavam na contestação das ações do governo racista de remoção ealocação indiscriminada de terras rurais e urbanas. Uma das mais importantes foi a Association for Rural Advancement (AFRA), fundada em 1979 para contestar as remoções de comunidades negras para as reservas ou bantustões ${ }^{15}$ na área da antiga província de Natal. Dos projetos promovidos pela AFRA, surgiram os primeiros comitês de pessoas afetadas pelas políticas de terra do apartheid. De tais comitês saíram as principais lideranças do Landless People's Movement, mais de 20 anos depois. ${ }^{16}$

Essas ONGs e suas campanhas procuraram associar as práticas discriminatórias de remoção às condições de vida deterioradas tanto nas zonas de reservas quando nos espaços urbanos (townships), para onde muitas das famílias foram deslocadas. Tendo vários de seus membros como militantes de partidos de oposição, foram as demandas dessas ONGs que, segundo James (2007, p.34), orientaram as políticas do Congresso Nacional Africano (ANC) nas suas negociações para o final do apartheid. ${ }^{17}$

A questão da terra colocou, de um lado, os proprietários brancos que defendiam uma política

${ }^{15}$ A AFRA tem sua base de atuação apenas na província de Kwazulu-Natal, uma das nove que passaram a compor o país ao final do apartheid.

16 "Muitos dos debates iniciais sobre a reforma da terra ignoram a participação dos sem-terras. Os sem-terras marginalizados apenas ganharam acesso aos debates sobre esse tipo de política por meio de eventos patrocinados por ONGs, como a campanha "De volta para a terra", de 1993, e a Conferência de Terras da Comunidade, de 1994. Ambos os eventos foram organizados pelo Comitê Nacional da Terra (NLC), uma ONG de defesa dos direitos à terra com sede em Johhanesburg". (Alexander, 2004, p.13). Tradução do autor.

${ }^{17}$ As ONGs tiveram um papel particularmente importante na elaboração e implementação do programa de reforma da terra. Elas emergiram em um contexto no qual as comunidades ameaçadas de remoção (trabalhadores rurais expulsos de fazendas onde trabalhavam e viviam ou pequenos proprietários removidos pela política eliminadora dos chamados black spots) necessitavam de ajuda para se defender das ações do Estado". (James, 2007, p.35). Versão do autor. 
agrária presentista que salvaguardasse os interesses do setor comercial e, de outro, as ONGs que postulavam uma política de terras orientada por um passado de perda ou “despossessão” racialmente orientada. ${ }^{18} \mathrm{O}$ resultado dessa controvérsia foi a incorporação da questão da terra na constituição do país, da seguinte forma:

Uma pessoa ou comunidade cuja posse da terra tenha se tornado legalmente frágil como resultado de práticas ou das leis racialmente discriminatórias do passado tem o direito, por um Ato do Parlamento, a uma posse que seja legalmente assegurada ou a uma reparação compatível.

Uma pessoa ou comunidade cuja propriedade foi tomada depois de 19 de junho de 1913, como resultado das práticas ou leis discriminatórias, tem o direito, por um Ato do Parlamento, a uma posse que seja legal ou a uma compensação compatível (James, 2007, p.5).

A questão da terra foi vista como uma questão de reparação de direitos sociais ao contingente de pessoas agredidas pelas políticas segregacionistas. Antes de tudo, visava-se a garantir a equidade em termos de posse do território. Uma série de leis, atos e emendas constitucionais veio a regulamentar essa política, cujo objetivo mais geral era retornar $30 \%$ das terras do país para as mãos de pessoas negras. ${ }^{19}$ Para muitos dos analistas locais, essa forma de incorporação do direito à terra ao texto constitucional ficou conhecida como o rights based approach. $^{20}$

Em um documento apresentado no ano de 2006 pela ministra da agricultura, em um evento organizado pela Food and Agriculture Organization (FAO), vemos claramente os sentidos que a política de terras sul-africana adquire para o próprio governo:

Despertando em uma sexta-feira pela manhã, dia 20 de junho de 1913, os nativos da África do Sul se encontraram, não verdadeiramente como escravos, mas como párias em sua terra natal.

${ }^{18}$ Uma breve descrição dessas negociações e da posição adotada pelo ANC pode ser encontrada em Ntsebeza (2005).

${ }^{19}$ Sobre a legislação referente ao tema da terra na África do Sul, ver Claassens e Cousins (2008).

${ }^{20} \mathrm{Em}$ português, "uma abordagem baseada na garantia de direitos".
Essas são as palavras do senhor Sol Plaatjie, o primeiro secretário geral do Congresso Nacional Africano, retiradas de seu livro "A vida nativa na África do Sul”. Naquela data, o decreto 27 de 1913 delineou uma divisão clara entre as explorações brancas e negras, segregando territorialmente europeus e africanos. Lavouras negras somente seriam permitidas nas "reservas nativas", compreendendo 8\% das terras de todas as terras daquele tempo. Em 1936, o Decreto de Associações e Terras Nativas (decreto 18 de 1936) adicionaria mais 6 milhões de hectares, destinando um total de $13,7 \%$ da área total do pais. Em 1994, o mesmo padrão altamente desigual de propriedade da terra continua vigente. Esse é o legado do apartheid que o novo governo democrático começou a tentar resolver quando chegou ao poder (DLA, 2006).

Se a questão da terra foi sendo tratada pelos actantes (ONGs, Estado e pesquisadores) da forma como vimos acima, nada mais lógico que a associação entre o colonialismo e o apartheid entendidos como processo de destituição - como fundamental para o conceito e o sentimento do sem-terra sul-africano no pós-apartheid. Na África do Sul, o processo de perda de terras é fortemente associado à perda de direitos formais de uso do solo do país. É nesse contexto de associações que devemos colocar as definições lançadas pelo LPM em seus manifestos a partir de 2001. As provas e os objetos de que o movimento tem lançado mão tornam sua ação justificável diante de uma quadro de disputas que se estabeleceu na África do Sul dos últimos 100 anos, e que alcança seu ápice ao final do apartheid. A referência ao texto clássico de Sol Plaatjie é, nesse caso, equivalente às narrativas sociológicas brasileiras citadas acima. "Native Life in South Africa" ajudou a conformar os parâmetros dentro dos quais a relação com a terra seria enquadrada e narrada sociologicamente naquele país. $^{21}$

Ao contrário do que observamos no caso do MST, em nenhum momento o LPM apoia suas provas em alicerces como trabalho, produção ou agricultura. Seus inimigos públicos também não são os latifúndios. Não porque os membros do LPM

${ }^{21}$ Essa narrativa é classificada por Walker (2008) como a "master narrative", que orienta toda a estrutura do programa de reforma da terra sul-africana. 
não se interessem pela terra ou porque os latifundiários não sejam um entrave à sua luta. A ausência desse tipo de prova não invalida que tenham aspirações agrárias, mas nos mostra qual o universo de grandezas legítimas na situação de demandas por reparação das injustiças do passado.

\section{OBJETOS POSTOS À PROVA: bandeiras e seus significados}

Como apontou Lygia Sigaud (2000), o hasteamento de uma bandeira se tornou, no Brasil, um elemento central das disputas por terra. Colocar bandeira em uma área ocupada aponta qual o movimento e qual o tipo de organização de cada acampamento. No caso sul-africano, não há ocupações de terras ou acampamentos, mas manifestações tais como marchas, sit-in em prédios públicos, velórios e julgamentos. ${ }^{22}$ Em todos esses casos, as bandeiras são o sinal diacrítico que aponta o autor e tipo de demanda que está sendo realizada. Ela indica que tipo de coletividade e que tipo de questão estão postas em jogo.

Ao lançar o olhar, como na Figura 1, para as duas bandeiras, reconhecemos facilmente correspondências entre elas. Suas cores, proporcionalidades e figuras deixam claro que a bandeira dos sul-africanos tem alguma relação com a do movimento brasileiro. ${ }^{23}$

Como podemos ver na foto acima, tirada no dia em que o LPM promoveu e comemorou o enterro de uma de suas militantes sem a permissão do fazendeiro (dono da área onde residia sua família), as bandeiras dizem não apenas de quem é o protesto, mas com quem os manifestantes se aliam (Borges, 2011). De fato, a bandeira do MST apareceu

${ }^{22}$ Ao longo dos últimos cinco anos, as ações mais frequentes que envolveram o LPM eram os enterros de pessoas ligadas ao movimento que viviam dentro de fazendas de brancos que não permitiam esse tipo de ritual; e também mobilizações para acompanhar julgamentos judiciais de casos de conflitos entre donos de terras e moradores de fazenda.

${ }^{23}$ O texto de Mnxitama (2006), um dos fundadores do LPM, deixa claro como o movimento foi influenciado por seu parceiro brasileiro. em todos os eventos públicos do LPM entre 2005 e 2009. Apesar de tremularem juntas e serem muito similares, as duas bandeiras são, no entanto, ícones e conjuntos que refletem também os distintos contextos nacionais de disputa. Suas diferenças e similaridades também nos ajudarão a trazer novos elementos para nossa análise sobre os sentidos de ser sem-terra.

Ambos os movimentos, em seus documentos públicos, atribuem um lugar específico para explicar o significado de suas flâmulas, tanto pelas cores, como pelas imagens utilizadas. Em cada um dos casos, como veremos abaixo, elementos que poderiam ser pensados como similares adquirem sentidos muito diferentes quando utilizados para justificar a luta de cada movimento.

Para o MST, a bandeira adotada a partir de 1987 é composta pelo seguinte conjunto de símbolos e significados: vermelho, que representa o sangue que corre em nossas veias e a disposição de lutar pela Reforma Agrária e pela transformação da sociedade; branco, que representa a paz pela qual lutamos e que somente será conquistada quando houver justiça social para todos; o verde representa a esperança de vitória a cada latifúndio que conquistamos; o preto representa o nosso luto e a

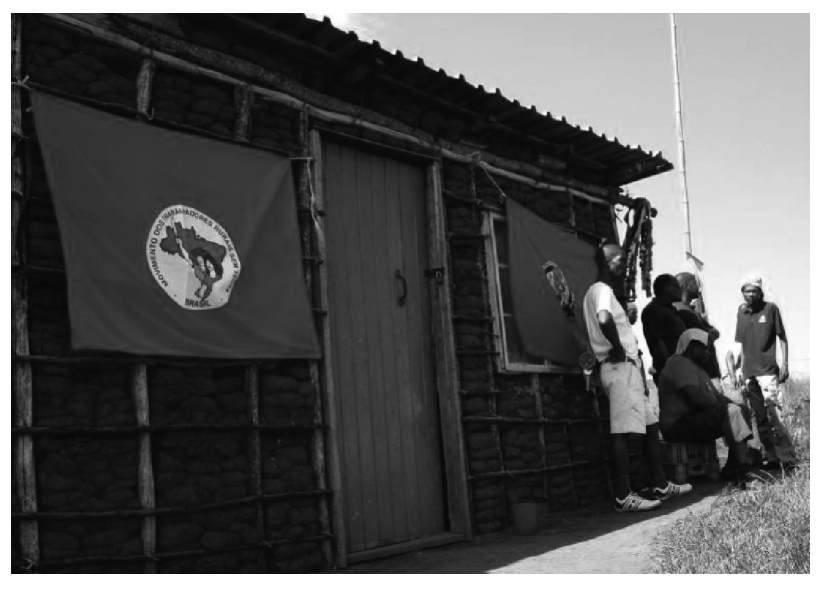

Figura 1 - Bandeiras do LPM e do MST em protesto organizado pelo M em 2007, na província de Kwazulu-Natal.

nossa homenagem a todos os trabalhadores e trabalhadoras que tombaram, lutando pela nova sociedade; o mapa do Brasil representa que o MST está organizado nacionalmente e que a luta pela 
Reforma Agrária deve chegar a todo o país; trabalhador e trabalhadora representam a necessidade da luta ser feita por mulheres e homens, pelas famílias inteiras; o facão representa as ferramentas de trabalho, de luta e de resistência.

Na constituição interina do LPM, as cores e objetos aparecem definidos na seguinte ordem e da seguinte forma: preto - pelas massas; verde pela nossa terra; vermelho - pelo sangue derramado por nossa terra; branco - pela paz que lutamos e que será conseguida assim que houver terra e alimentos para todos; logomarca - o logo do LPM deverá ser uma mulher e um homem liderando uma marcha de sem-terras sobre um fundo vermelho e verde, colocados dentro do símbolo do poder das mulheres, cercado pelo nome do Landless People's Movement e pelo slogan: Terra já! Organizar e unir! A mulher deverá estar segurando uma bandeira do LPM em uma mão e com o punho da outra mão cerrado. O homem deverá estar segurando uma ferramenta agrícola e com o punho da outra mão cerrado.

prio ordenamento das cores: no caso de LPM revela o sentido da pergunta que abre este texto. A primeira cor mencionada é a preta. Ela serve para simbolizar as massas e não o luto, como no caso do MST. A luta do LPM, assim como atesta a cor da pele do homem e da mulher presentes no seu logo, é uma luta dos negros sul-africanos. Já no logo do MST, temos um homem e uma mulher brancos conferindo legitimidade à sua luta.

A cor dos personagens e o uso da cor verde nos revela uma ordem de grandezas de suma importância na história de cada luta. Enquanto, para o MST, o verde significa a terra conquistada do latifúndio, para o LPM, a terra é aquela pertence aos nativos da África do Sul, desde antes da colonização. Isso nos conduz ao próprio tempo histórico no qual se inscrevem essas definições. O MST não reclama uma terra que já foi de seus representados, como o faz o LPM, seguindo a lógica do memorável texto de Sol Plaatjie. O MST quer tomar, para si, uma terra agora ocupada pela grande lavoura.

\section{COLONIALISMO E COLONIZAÇÃO: quando o indígena é ou não sem-terra}
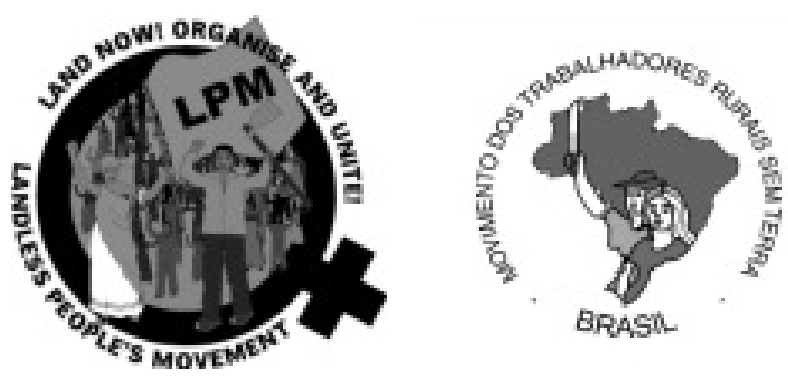

Comparando a forma como as bandeira são apresentadas, encontramos algumas semelhanças e também muitas diferenças que nos remetem aos contextos de luta descritos na parte anterior. Entre as semelhanças, vemos o branco como sinônimo de paz, o fato de mulheres e homens estarem lado a lado (o homem sempre com o instrumento de trabalho na mão) e até o vermelho do sangue que anima e é derramado nas lutas por terra.

As diferenças começam a aparecer no pró-
Outro elemento que parece ser impor-
tante para compreender os distintos regimes de justificação em ambos os países é o uso de termos como colonização e colonialismo. Quando o sem-terra sul-africano perguntou ao seu colega brasileiro sobre as razões de um branco se considerar e ser considerado um legítimo sem-terra no Brasil, era também a essas diferenças que ele aludia. Como vimos, na sua bandeira, nos seus documentos e nos seus discursos, o LPM agencia uma série de objetos que procuram provar que a situação atual de seus membros é fruto direto do colonialismo.

No universo de grandezas no qual se inscreve o MST e suas demandas, a questão colonial ganha obrigatoriamente outros contornos. Se lembrarmos que a mobilização que deu origem ao movimento era chamada de "movimento dos colonos", podemos começar a entender que o MST não 
pode negar o colonialismo, sob pena de invalidar sua própria existência: o colono, no discurso do MST, é aquele que também sofre os efeitos deletérios da grande propriedade agrícola. Outra vez, as provas apresentadas pelo MST não surgem do autointeresse, mas de um universo de grandezas muito peculiar. Se, na África do Sul, o termo corrente é colonialismo, no Brasil, temos adotado-em termos de sociologia e de movimentos sociais-muito mais frequentemente a ideia de colonização. ${ }^{24}$ Sem precisar retornar ao mundo dos clássicos do pensamento social brasileiro, anteriormente referido, poderíamos apenas lembrar que suas críticas ao latifúndio se fundam na associação desse tipo de uso da terra a um processo específico de colonização: aquela baseada na grande lavoura de exportação. Em momento algum, comoé recorrente na literatura sul-africana, a sociologia e os movimentos políticos brasileiros colocam em xeque o colonialismo como prática ilegítima. Alguns autores, como Sérgio Buarque de Hollanda, por exemplo, criticaram o tipo de colonização e administração implantado por Portugal, comparando nosso caso com os das colônias espanholas. Porém o colonialismo, em si, não foi posto em questão. Nessa chave de pensamento, o que interessa é compreender os limites e pensar em maneiras de reconstruir ou redirecionar o processo de colonização, que foi uma matriz ingrata.

Não precisamos fazer muito esforço para compreender que o sem-terra, assim como os cientistas sociais brasileiros consideram, são frutos do processo colonial, mas nem um nem outro se associam a uma ideia de nativos ou indígenas. ${ }^{25}$ Isso não significa que o MST não reconheça as lutas por terras de outros agentes como os indígenas e descendentes de escravos africanos (quilombolas). Pelo contrário, o MST expressa publicamente a legitimidade desses grupos e de suas lutas, mas, por questões históricas, não os classifica como sem-terras.

${ }^{24}$ É digno de nota o fato de teorias como o pós-colonialismo e o de-colonialismo terem pouca influência em nossa sociologia, comparado com o que acontece na África, Ásia e boa parte dos demais países da América Latina.

${ }^{25}$ É importante notar que, até os dias de hoje, foram poucos os representantes da população indígena brasileira que se tornaram cientistas sociais ou líderes políticos nacionais.
É exatamente o contrário disso que ocorre no caso sul-africano. Como a população negra é a maioria (muito mais no LPM do que dentre os intelectuais que publicam sobre ele), categorias como essas são tomadas de assalto dos colonizadores para constituírem armas de grandeza sem igual. Ser nativo, ser negro, ser africano é ser vítima da expropriação mais do que qualquer outro, e essa condição de grandeza anula qualquer objeto ligado ao mundo da produção, do mercado ou da economia. A reforma de terra (defendida pelo LPM) remete, assim, a um universo de grandezas que não encontra equivalente na ideia de reforma agrária, entendida no sentido de aptidão para agricultura, como vimos em uma das definições oferecidas por uma liderança do MST.

No universo sul-africano, a relação com a terra ultrapassa a cronologia da nação - como constatam, com incompreensível estupefação, autoras como Walker (2008) e James (2007) - e leva a uma reivindicação que coloca em disputa o próprio sentido da terra como unidade de produção. No Brasil, o que está em disputa é o tipo e qualidade da produção (em seus diversos sentidos sociológicos) que irá se desenvolver. O que se defende é uma produção que permita uma maior divisão social do uso da propriedade e da terra.

\section{CONSIDERAÇÕES FINAIS: a reforma agrária, a questão da terra e a sociologia branca}

Não há qualquer novidade em dizer que a sociologia é uma ciência social branca - em todos os sentidos possíveis. Talvez a principal diferença com a antropologia social mais tradicional (colonialista) é que essa última era uma ciência dos brancos sobre os não-brancos - outrora chamados até de nativos; enquanto que a sociologia sempre se pensou como uma ciência dos brancos sobre eles mesmos. ${ }^{26} \mathrm{O}$ fato de já sabermos isso, no en-

${ }^{26}$ Certamente, a sociologia nunca usou o termo branco para se definir. Ao invés disso, preferiu termos ou processos como modernidade, secularização, revolução ou racionalização, que nunca deixaram de se confundir com a cor dos sujeitos que os engendravam. 
tanto, não nos levou a incorporar esse obstáculo epistemológico ao centro de nossas reflexões e ações políticas. Ao contrário, a naturalização hegemônica e opressora de uma cor, uma forma de pensar, de trocar, de reivindicar e de se organizar ofuscou qualquer dissonância empírica que viesse a desestabilizar essa mesma epistemologia branca, única autorizada para pensarmos nossos objetos.

A questão levantada pelo sem-terra sul-africano para seus colegas brasileiros trazia esse obstáculo em toda sua potência. Nenhum brasileiro ali presente - pesquisador ou militante - jamais havia pensado naqueles termos. Neste texto, procuramos mostrar como a análise daquela situação pode ser interpretada, nas palavras de Boltanski (2000), como uma disputa na qual a cor do semterra foi usada para justificar a luta do LPM. Ao mesmo tempo, ela serviu para tensionar o papel do militante branco do MST e para despertar uma análise dos objetos e das provas que constituem a própria sociologia das lutas por terra no Brasil e na África do Sul do último século.

Quando Moyo e Yeros (2005) cunham a expressão recuperando a terra para descrever o ressurgimento dos movimentos rurais no que agora vem sendo chamado de sul, eles estão descrevendo um processo de mobilização cujo ícone maior é esse objeto chamado terra. Ao estudar o encontro entre dois dos movimentos que também aparecem na obra desses autores, percebemos que, apesar de estarem orientados pelo mesmo ícone (a terra) e fazerem da sua falta uma identidade de mobilização, os agenciamentos empreendidos localmente são bastante diferentes. As grandezas associadas à terra são de magnitudes incomparáveis. Tais diferenças apontam para um conjunto de objetos e provas que tem servido para justificar que exista uma questão da terra e, principalmente, de movimentos que lutam por ela. Além disso, entram, nessas disputas, actantes como o Estado, ONGs e os próprios cientistas sociais, para limitar os exemplos ao escopo do que tratamos neste texto.

Tornar a questão da terra como central no Brasil é associá-la diretamente a uma transformação do espaço social em direção a uma forma dife- rente de organização produtiva. Vimos, ao longo do texto, que, em suas atividades críticas, o MST tem lançado mão de termos como o latifúndio, agricultura e principalmente reforma agrária como objetos que os legitimam diante daqueles que desejam mobilizar e também diante de actantes como os governos, os acadêmicos e outras organizações. Associando, de forma dinâmica, termos que, para muitos dos analistas do caso brasileiro, sempre formaram parte de um mesmo conjunto, o MST nos dá pistas para entender quais as grandezas de ser um sem-terra. Tais grandezas não são exatamente congruentes com duas questões fundamentais para o LPM: o fato de serem indígenas e negros.

O significado da cor preta na bandeira do LPM foi peça essencial para conhecermos melhor as equivalências sul-africanas em relação à experiência brasileira. Lá, o sem-terra é, sobretudo, negro. Ser negro na África do Sul é ser vítima do colonialismo e do apartheid. Ser negro é ser indígena e querer ter uma terra que foi roubada de seus ancestrais (Borges, 2011). A associação entre esses diferentes objetos utilizados em situações de disputa por terra constroem um sentido de justiça que passa por uma reforma do espaço rural que não pode ser equivalente ao agrário. O objeto agrário (nas mesmas equivalências que aparecem no caso do MST, por exemplo) não deixa de ter valor na África do Sul, porém, tendo em vista o fato de serem os colonizadores brancos que, nessa mesma disputa, o mobilizam nesse sentido, sua grandeza é menor. É menor porque, além de ser sinônimo de branco, o agrário é também equivalente ao colonialismo naquele contexto político específico.

Entenderemos melhor ainda essas disputas se pensarmos que, na África do Sul, há um ministério dedicado aos "assuntos da terra" e que nele se encontram todas as políticas de reorganização da distribuição do território no pós-apartheid. ${ }^{27}$ Enquanto isso, no Brasil, o ministério responsável pelo mesmo objeto se dedica ao "desenvolvimento agrário".

As breves referências ao encontro entre

${ }^{27}$ Department of Land Affairs. 
Landless People's Movement e o Movimento dos Trabalhadores Rurais Sem-Terra mostram como a sociologia sempre esteve muito mais equipada e confortável para tratar do MST e do agrário, do que do LPM e da terra. Esse desconforto não se refletiu apenas no estranhamento da associação entre sem-terras e indígenas, que foi imposto a mim e ao MST na pesquisa. Ele permeia todos os trabalhos recentes que procuraram compreender os sentidos e os impactos do compromisso com a redistribuição de $30 \%$ do solo sul-africano. Autores como Ntsebeza (2007) tentam chamar a atenção para o fato de que a questão da terra é sobretudo uma questão de direitos e que não se pode desconectar essa questão dos programas de Estado. Por outro lado, autores como Cousins (2009), Walker (2008) e James (2007), reproduzindo um modo equivalente ao brasileiro de olhar para a questão da terra, irão concentrar suas análises na falha do Estado em transformar a questão da terra em questão agrária, ou seja, em promover aquilo que chamam de desenvolvimento rural. ${ }^{28}$ Esse desencontro talvez seja o mesmo experimentado pelo militante do MST quando visitou seus colegas do LPM. Na África do Sul, o sem-terra e suas lutas não são necessariamente agentes do desenvolvimento agrário. Já no Brasil, não há dúvidas de que o MST tem desempenhado esse papel.

Desse contraste, aprendemos que é preciso ter cuidado para não considerar as lutas dos semterra como se justificáveis apenas quando associadas ao agrário, como vemos predominar na sociologia em geral (excluindo a etnologia e os emergentes estudos sobre quilombolas no Brasil, que nunca aparecem associados à ideia de sem-terra). Fugir dessa associação - política e sociológica - nos permitiria ver que esses movimentos, agora associados, possuem projetos políticos distintos para o futuro dos sem-terras que representam. Um é orientado para a reforma agrária; o outro para a

${ }^{28}$ Esses autores concentram suas críticas na ideia de land reform como um política pública de garantia de direitos (rights based aproach). Para eles as políticas do governo sul-africano e as lutas do LPM (James, 2007) não têm sido capazes transformar as condições materiais de existência nas zonas rurais do Brasil. reforma da terra. E isso não só não os afasta, como cria obstáculos epistemológicos estimulantes para as ciências sociais.

(Recebido para publicação em 22 de março de 2011) (Aceito em 11 de maio de 2011)

\section{REFERÊNCIAS}

ALEXANDER, A. Rights beyond the urban-rural divide: South Africa's landless people's movement and the creation of a landless subject. Durban: UkZN, 2004. Disponible en: www.ukzn.ac.za/ccs. Aceso en: 12 feb. 2012.

Not the democracy we struggled for: the landless people's movement and the politicisation of urban-rural division in South Africa. 2004. 194f. Honors Thesis, Harvard: Harvard College, 2004.

ALVES, B. A política agrária de Leonel Brizola no Rio Grande do Sul: governo, legislação e mobilização. 2010. 86 f. Dissertação (Mestrado em Ciências) - Curso de PósGraduação em Ciências Sociais em Desenvolvimento, Agricultura e Sociedade da Universidade Federal Rural do Rio de Janeiro, CPDA 2010. Disponível em: http:// r1.ufrj.br/cpda/wp-content/uploads/2011/08/ dissertacao_bernard_jose_pereira_alves_2010.pdf

BALLETTI, L. et al. Late mobilization: transnational peasant networks and Grassroots Organizing in Brazil and South Africa. Journal of Agrarian Change, [S.l.], v.8, n.2-3, p.290-314, apr./july, 2008

BOGO, A. Sem-terra. In: MOTTA, Márcia. Dicionário da terra. Rio de Janeiro: Editora Record, 2004.

BOLTANSKI, L.; THEVENOT, L. De la justification. Paris: Galimard, 1991.

. El amor y la justicia como competências. Buenos Aires: Amorrotu, 2000.

BORGES, A. Sem sombra para descansar: etnografia de funerais na África do Sul. Anuário Antropológico 2010/I, dez. 2011.

CAMARGO, A. A. Brésil nord-est: mouvements paysans et crise populiste. 1973. Tese de (Doutorado) - Universidade de Paris, 1973.

CLAASSENS, A. COUSINS, B. Land power and custom: controversies generated by South Africa's Communal Land Rights Act. Cape Town, UCT Press, 2008.

COUSINS, B. Land reform in South Africa. Journal of Agrarian Change, [S.1.], v.9, n.3, 2009. p.421-431.

GEHLEN, I. Uma estratégia camponesa de conquista da terra e o Estado: o caso da Fazenda Sarandi. 1983. Dissertação (Mestrado em Sociologia) - Universidade Federal do Rio Grande do Sul. Porto Alegre, 1983.

HALL, R. Another Countryside? Policy options for land and agrarian reform in South Africa. Cape Town: School of Government, University of the Western Cape, 2008.

JAMES, D. Gaining Ground: "rights" and "property" in South African land reform. Londres: Routledge-Cavendish, 2007.

LATOUR, B. Reassembling the social an introduction to actornetwork-theory. Oxford: Oxford University Press, 2005.

MAFEJE, A. The ideology of tribalism. The Journal of Modern African Studies, Cambridge, v.9, n.2, p.253-261, 1971. 
MÉLIGA, L. D.; JANSON M. D. C. Encruzilhada natalino. Porto Alegre: Vozes, 1982.

MNGXITAMA, A. The taming of land resistance: lessons from the National Land Committee. Journal of Asian and African Studies, [S.l.], Sage, n.41, p.39-69, 2006.

MOYO, S.; YEROS, P. The resurgence of rural movements under Neoliberalism. In

(Ed.) Reclaiming the land: the resurgence of rural movements in Africa, Asia and Latin America. London: Zed Books, 2005.

STÉDILE, J. P. MST. Programa de Reforma Agrária do MST 1984. In: A questão agrária no Brasil 3. Programas de reforma agrária: 1946-2003. São Paulo: Expressão Popular, 2005.

NTSEBEZA, L. Democracy compromised: chiefs and the politics of land in South Africa. Brill: Leiden, 2005.

; HALL, R. The land question in South Africa: the challenge of transformation and redistribution. Johannesburg: HSRC Press, 2007.

PALMEIRA, M. Latifundium et capitalisme au Brésil: lecture critique d'un debat. 1971. Thèse (3ème Cycle) Faculté des Lettres et Sciences Humaines de l'Université de Paris, 1971.

PRADO JR. C. A questão Agrária. In: STÉDILE, J. P. A questão agrária no Brasil 3. Programas de reforma agrária: 1946-2003. São Paulo, Expressão Polular, [1960] 2005

ROSA, Marcelo. Oligarquias agrárias, o Estado e o espírito do neoliberalismo no Brasil. In: GRIMSON: Alejandro (Org.) Cultura y neoliberalismo. Buenos Aires: Clacso, 2007. p.111-125, 2007
Estado e ações coletivas na África do Sul e no Brasil: por uma sociologia contemporânea dos países não exemplares. Sociologias, Porto Alegre, UFRGS, v.20, p.292318, 2008.

Sem-terra: os sentidos e as transformações de uma categoria de ação coletiva no Brasil. Lua Nova, São Paulo, Cedec, n.76, p.197-227, 2009.

SANTOS, R. Questão agrária e politica: autores pecebista, org. e estudo introdutório Feudalidade e prussianismo no pensamento agrário do PCB. Seropédica, Rio Janeiro, Universidade Federal Rural do Rio de Janeiro, 1996.

SIGAUD, L. A forma acampamento: notas a partir da versão pernambucana. Novos Estudos Cebrap, São Paulo, n.58, p.73-92, 2000.

et al. Ocupações de terra, acampamentos e demandas ao Estado: uma análise em perspectiva comparada. DADOS: revista de Ciências Sociais, Rio de Janeiro, v.51, n.1, p.107-142, 2008.

SCHILLING, P. Do caminho brasileiro de reforma agrária 1962. In: Stedile, J. P. A questão agrária no Brasil 1. São Paulo: Expressão Popular, 2005.

THÉVENOT, L. L'action au pluriel: sociologie des régime d'engagement. Paris: La Découverte, 2006.

WALKER, C. Landmarked: land claims and restitution in South Africa.Ohio: University of Ohio Press, 2008. 


\section{AGRARIAN REFORM AND LAND REFORM: social movements and the sense of being a landless worker in Brazil and South Africa}

\author{
Marcelo C. Rosa
}

This article presents the results of a comparative research developed between 2005 and 2009 on the actions of the South African Landless People's Movement (LPM) and the Brazilian Landless Rural Workers' Movement (MST). In Brazil, the concept of an agrarian reform prevails, that is, a political action towards a productive agricultural use of the land, having the productivity criteria as its main frame of reference. In South Africa, the conflict is structured under the term of land reform, a slogan that refers to the changes in territory distribution, aiming to make up for the harm caused by apartheid. Thus, we point out that each case involves different types of subjects within their political actions. By having different historical agents as their reference, the movements analyzed in both countries attempt to gain legitimacy through particular dimensions that justify their existence and struggle. In this article, we intend to show the specificities of the landless workers in each movement, according to the forms of "social elevation and justification" regarding their peers and the State.

KEY-wORDS: landless workers, agrarian reform, South Africa, social movements, MST.

\section{RÉFORME AGRAIRE ET LAND REFORM: les mouvements sociaux et la raison d'être un paysan sans-terre au Brésil et en Afrique du Sud}

\author{
Marcelo C. Rosa
}

Cette étude présente les résultats d'une recherche comparative faite entre 2005 et 2009 sur le rôle des Landless People's Movement (LPM), en Afrique du Sud, et le Mouvement des Travailleurs Ruraux Sans Terre (MST) au Brésil. Du côté brésilien l'idée de réforme agraire domine, c'est-àdire celle d'une action politique visant une utilisation productive ou agricole des terres avec, comme toile de fond, des critères légaux de productivité. En Afrique du Sud, la lutte se base sur une nomemclature de land reform, slogan qui fait appel à un changement au niveau de la distribution des terres afin de réparer les injustices commises par les gouvenements de l'apartheid. Il est donc important de faire remarquer que ces deux cas se rapportent à des types différents de sujets de l'action politique. Vu notre référence à des agents historiques distincts, nous pouvons dire que les mouvements analysés dans ces deux pays cherchent leur légitimation dans des "grandiosités" différentes, qui justifient leur existence et leurs luttes. Dans cet article, sous essayerons de montrer les spécificités de chaque paysan sans terre appartenant à ces mouvements, à partir de leurs manières de "se mettre en valeur et de se justifier socialement” face à leurs bases et à l'État.

MoTs-CLÉs: paysans sans-terre, réforme agraire, Afrique du Sud, mouvements sociaux, MST.

Marcelo C. Rosa - Doutor em Sociologia. Professor Adjunto no Departamento de Sociologia da Universidade de Brasília - UNB. Coordenador do Programa de Pós-Graduação em Sociologia na mesma universidade. Pesquisador Bolsista de Produtividade Nivel 2 do CNPq. Atuou como professor vistante na Universidade de Cape Town (Africa do Sul) e na Universidade de Buenos Aires (Argentina). Tem experiência na área de Sociologia, atuando principalmente nos seguintes temas: teoria sociológica, movimentos sociais, mudança social. Nos últimos anos suas atividades de ensino e pesquisa têm sido direcionadas para uma sociologia das formas não-exemplares que as ações coletivas e o Estado ganham nos países africanos e latino-americanos. É coordenador do Laboratório de Sociologia Não-exemplar. 